Reprinted from Degges-White, S., \& Myers, J. E. (2005). The Adolescent Lesbian Identity

Formation (ALIF) model: Implications for counseling. Journal of Humanistic Counseling, Education and Development, 44, 185-197. The American Counseling Association. Reprinted with permission.

No further reproduction authorized without written permission from the American Counseling Association: http://www.counseling.org/

\title{
RESEARCH
}

\section{The Adolescent Lesbian Identity Formation Model: Implications for Counseling}

\author{
SUZANNE E. DEGGES-WHITE \\ JANE E. MYERS
}

An interview protocol based on V. Cass's (1979) sexual identity formation work was used with 13 self-identified lesbians. Data analysis yielded a sexual identity formation model similar to J. E. Marcia's $(1966,1987)$ identity development model. Potential emotional and physical health risks for each phase of the model are discussed, and interventions are suggested.

Women who self-identify as lesbian represent a significant and invisible minority (Fassinger, 1991) with current estimates suggesting that as many as $3.6 \%$ of the population, or 2,300,000 women, are lesbian (Diamond, 1999). Even with a number this significant, prejudice against lesbians and gay males seems to be the only "politically correct" bias still in existence (Whitley \& Ægisdóttir, 2000). Over the past 30 years, there has been a noticeable decrease in society's willingness to overtly express a racial prejudice (Gallup \& Hugick, 1990), but the level of prejudice expressed against nonheterosexual individuals has been relatively stable (Yang, 1997). Occurrences of verbal harassment among gay and lesbian college students run as high as $26 \%$ having experienced verbal insults, $26 \%$ having been threatened with physical assault, and $23 \%$ having been victims of physical violence (D'Augelli, 1989). Recent research (Tomeo, Templer, Anderson, \& Kotler, 2001) indicates that adolescent lesbians are victims of sexual molestation more frequently than heterosexual female adolescents and are more likely to have been active in prostitution activities than their heterosexual counterparts. Although these figures are reported by young adults and the numbers might be significantly higher for men and women who are significantly older and have lived through even less tolerant times, they do reflect the significant challenges in adopting a lesbian identity in the face of potential and actual violence or abuse.

Suzanne E. Degges-White, School of Education, Purdue University Calumet; Jane E. Myers, Department of Counseling and Educational Development, University of North Carolina at Greensboro. Correspondence concerning this article should be addressed to Suzanne E. DeggesWhite, School of Education, Purdue University Calumet, 2200 169th Street, Hammond, IN 46323 (email: dwhites@calumet.purdue.edu). 
Adolescents normatively are faced with the need to develop an identity (Erikson, 1968; Marcia, 1966, 1987) with associated risks to their mental health and well-being; developing a separate identity as a sexual minority may create additional, significant, and seemingly insurmountable mental health obstacles (D'Augelli, Hershberger, \& Pilkington, 1998; Morrison \& L'Heureux, 2001;Safren \& Heimberg, 1999). Counselors working with such female adolescents need to be sensitive to possible sexual minority issues (Taylor, 2000) and to provide appropriate interventions when working with this at-risk population. Cass (1979) published the first and most widely used model of sexual identity formation(McCam \&Fassinger, 1996). She proposed that individuals go through a process consisting of six stages when they are considering, experiencing, or embracing a sexual minority identity. Although Cass's model provided an affirming (Frable, 1997) and sophisticated approach (Cox \& Gallois, 1996) to gay identity development, the model has been criticized for shortcomings related to lesbian identity development. Specific criticisms include that it was developed for gay men; was too rigid in its linear progression; was based on the assumption that lesbian attractions did not begin until puberty, rather than earlier in childhood; and was outdated (Akerlund \& Cheung, 2000; Degges-White, Rice, \& Myers, 2000; Hequembourg \& Farrell, 1999; Nichols, 1999; Whitman, Daskalos, Sobolewski, \& Padilla, 1998).

The purpose of this article is to describe an integrative model of lesbian identity development that is more fluid than Cass's (1979) model and more applicable to the sexual identity development of contemporary lesbians. The dual theoretical foundations of the model lie in the work of Marcia $(1966,1987)$ and Cass (1979), and it is supported by findings from a qualitative study (see DeggesWhite et al., 2000) in which adult lesbians were interviewed to examine the process of their sexual minority identity formation. A total of 12 interviews were included in the original study, and a 13th interview was subsequently conducted using the same protocol. Described in further detail below, these findings underscored the lack of fit of Cass's model for contemporary lesbians and the need for a new model that would be more useful for counselors, especially those working with female adolescents, and that could form the basis for counseling interventions. Based on the recurring themes, patterns, and experiences of these women, the presented model provides a good fit for the lesbian identity formation process. Examples of participants' responses and narratives from these interviews are cited in the descriptions of the stages of the Adolescent Lesbian Identity Formation (ALIF) model. Suggestions for further research and implications for counselors are discussed.

\section{THE DEVELOPMENT OF IDENTITY AND SEXUAL MINORITY IDENTITY: THE THEORETICAL PERSPECTIVES OF MARCIAAND CASS}

A central task of adolescent development is the formation of an identity. Marcia $(1966,1987)$ expanded on Erikson's (1968) basic concepts of identity versus identity diffusion in adolescence and developed a model of identity formation that 
is marked by four separate levels that merge the facing of a crisis, or a fork in the road, with a commitment to an identity. For individuals who have yet to face a crisis and have made no commitment to an identity, they are in a stage that is termed identity diffused. They have yet to cement an identity. Those who have not faced a crisis but have already made a commitment to a specific identity are considered to be identity foreclosed. Without having faced a crisis point or having had exposure to identity possibilities, they have prematurely committed to a particular identity choice. For individuals who have faced a crisis but have yet to commit to an identity, they linger in the identity moratorium stage. They are unwilling to commit to a specific path and are understood to be continuing to gather information. The last category consists of individuals who have faced a fork in the road and have worked through the crisis to develop a specific identity. The last category is considered to be the most developmentally healthy and is labeled identity achievement. Not every adolescent moves sequentially through these stages, and this parallels findings related to sexual identity development as described by Degges-White et al. (2000).

Cass (1979) developed a six-stage model of sexual minority identity development based on the internal congruence theory (Cox \& Gallois, 1996). As individuals move through each of the six stages, the interpersonal incongruence of the stage is hypothesized to provide motivation for further development. The first stage, identity confusion, is marked by recognition that one's behavior or feelings might be defined as homosexual. The second stage, identity comparison, reflects a tentative commitment to a homosexual identity. Identity tolerance is the third stage, and it is defined as a period in which the individual more strongly accepts his or her sexual minority identity. During this period, positive contacts with other sexual minorities may ease the way toward the fourth stage, identity acceptance. During this stage, additional contact with sexual minorities occurs as the individual seeks to connect with similar others. The following stage, identity pride, is described as a period of complete acceptance of one's sexual identity and awareness of society's rejection of gays and lesbians. During this stage, sexual identity is seen as one's primary identity, which can motivate an individual to activism and confrontation. Positive responses from heterosexuals are considered to be the motivator that moves an individual to the sixth stage, identity synthesis. This final stage is considered to be elusive for a great number of gays and lesbians, and it is marked by the integration of sexual identity into a more broad sense of self. Individuals either work through each stage, remain at a particular stage, or undergo identity foreclosure, terminating forward movement in the homosexual identity formation process (Cass, 1984).

Although the identity development models of Marcia $(1966,1987)$ and Cass (1979) have been studied extensively, no efforts have been made thus far to bring the concepts of the two authors together in the field of counseling. Moreover, neither model has been applied specifically to female adolescents struggling with the development of a sexual minority identity. Yet, it seems 
clear that both have value for understanding adolescents, especially young women trying to understand what it means for them to embrace an identity as a lesbian. The ALIF model represents an attempt to integrate these two theoretical approaches; the impetus for this integration came from an earlier qualitative study of lesbian identity development (Degges-White et al., 2000).

\section{INTERVIEWS WITH ADULT LESBIANS}

Degges-White et al. (2000) developed a qualitative study to assess the current validity of Cass's (1979) model. Cass's description of sexual identity stages was used as a guide to develop questions to assess lesbians' recollections of their identity development (see Appendix). Participants in that study were a convenience sample of adult women who identified themselves as lesbian. Initially, the researchers contacted nine individuals whom they knew personally who identified themselves as lesbian and requested their participation in the study. Additional participants were obtained by inviting initial participants to refer acquaintances of theirs who also identified as lesbian.

The structured clinical interviews allowed the participants to recount their personal coming-out history with minimal interference or guidance, and no self-rating or other quantitative measurements were included. The responses provided by the participants indicated that sexual identity development varies widely among individuals. Findings from the series of qualitative interviews teased out specific shortcomings of Cass's (1979) model to describe the identity development of lesbians today (Degges-White et al., 2000). Participants' experiences did not support the highly linear trajectory of identity development outlined by Cass (1979). Furthermore, the participants' developmental paths did not follow a universal sequential progression through each of the stages. Participants cycled through various stages of identity development, and their responses failed to support the validity of the fifth stage (identity pride). Many of the interview responses underscored adolescence as a critical, perhaps the most critical, period in the development of their identity as a lesbian. The challenges they presented made it clear that any model that would be useful for counselors in working with adolescents needed to combine both theories of identity development processes in general and theories of sexual minority identity development. Further analysis of the qualitative findings provided the framework for a developmental model based on similarities of participants' narratives and reflections on the coming-out process.

\section{THE ALIF MODEL}

The ALIF model, shown in Figure 1, is based on the identity development theory of Marcia $(1966,1987)$ and the results of qualitative interviews of adult lesbians who responded to structured questions based on Cass's (1979) model of sexual identity formation. The model includes four nonhierarchical, nonsequential phases of lesbian identity formation: identity achievement, iden- 


\begin{tabular}{|c|c|c|}
\hline \multirow{3}{*}{ No } & $\begin{array}{l}\text { Identity Diffused } \\
\text { Risky status marked by lack of focus } \\
\text { or experience/exploration }\end{array}$ & $\begin{array}{c}\text { Identity Foreclosure } \\
\text { Decision finalized before sufficient } \\
\text { experience }\end{array}$ \\
\hline & $\begin{array}{c}\text { Awareness of lesbian feelings, but not } \\
\text { committed to a lesbian or hetero- } \\
\text { sexual identity }\end{array}$ & $\begin{array}{c}\text { Awareness of attraction to women } \\
\text { but committed to a heterosexual } \\
\text { identity }\end{array}$ \\
\hline & "I feel different from other women" & "I am NOT a lesbian" \\
\hline \multirow{3}{*}{ Yes } & $\begin{array}{l}\text { Identity Moratorium } \\
\text { Decision put on hold until more } \\
\text { exploration }\end{array}$ & $\begin{array}{l}\text { Identity Achievement } \\
\text { Successful commitment to an } \\
\text { identity }\end{array}$ \\
\hline & $\begin{array}{l}\text { Have experienced a "deciding } \\
\text { moment" but not ready for total } \\
\text { commitment to a lesbian identity }\end{array}$ & $\begin{array}{l}\text { Have experienced a "deciding } \\
\text { moment" and subsequent } \\
\text { commitment to a lesbian identity }\end{array}$ \\
\hline & "Where would I fit in as a lesbian?" & "Coming out is a lifelong process" \\
\hline
\end{tabular}

\section{FIGURE 1}

\section{Adolescent Lesbian Identity Formation Model}

tity moratorium, identity foreclosure, and identity diffused. As is true in Marcia's model, the quadrants are divided by two dimensions: whether the individual has faced a crisis and whether she has committed to an identity. As is also true in Marcia's model, the upper two quadrants reflect less mentally healthy outcomes-identity foreclosure and identity diffused-and the lower two quadrants reflect a healthy identity status-identity achievement and identity moratorium.

\section{Identity Diffused}

An adolescent with a diffused identity is one who has not experienced a crisis and has not committed to an identity. This stage is characterized by a sense of difference from other female adolescents. Even from childhood, lesbians may feel quite different from their same-gender peers (Savin-Williams \& Lenhart, 1990). This sense of difference in adolescents may be marked by an attraction to other females and a sense of confusion about how to handle or respond to these feelings. This feeling of being different was described by participants in words such as "I don't fit in"; "what you don't understand, you hide outwardly-I was the all-American girl"; "very self-conscious, out-of-place"; "thought something was wrong with me"; and "didn't want to be made fun of." These feelings of not fitting in can be especially difficult for adolescents, who struggle with finding an acceptable identity regardless of sexual orientation. One participant expressed 
a strong desire to become "sexually active to attempt to understand the feelings other girls were talking about." This is often the case for those adolescents who are unsure yet of their sexual identity. They may feel shame, confusion, loneliness, and a sense of being unworthy.

This diffusion can often lead to unwanted sexual activity, especially for those young women who may possess a more masculine appearance. Masculinity in both heterosexual and homosexual women causes discomfort in society, and these adolescents are therefore treated differently. Some authors go so far as to state that masculine females are at greater risk of condemnation and sexual violence because they have crossed an imaginary line drawn by society as to what is acceptable for women in behavior and dress (e.g., McGann, 1999).

An adolescent with increasing awareness of her lesbian feelings may respond in one of three ways. She may completely shut down any further exploration or decision making, thus remaining in the diffusion stage. She may begin exploration if the opportunity presents itself, which is articulated as the previously mentioned crisis or fork in the road. This may lead to identity moratorium or eventual identity achievement. Conversely, she may respond in a highly negative manner and move into a state of identity foreclosure. This latter stage is discussed first.

\section{Identity Foreclosure}

Identity foreclosure occurs when an individual has not faced a crisis but has committed to an identity. This identity is accepted without opportunity for exploration and a decision based on experience. This phase is characterized by an awareness of same-sex attractions but a staunch commitment to a heterosexual identity. Some of the feelings that may accompany this awareness of lesbian feelings may be very dramatic. Participants described their initial reactions to their sexuality as feeling "like a sinner, going to hell" and "depressed and suicidal." Furthermore, they have responded to these feelings in such a way that they experienced a dramatic turnaround in their identity: "once a straight-A student, I flunked out of college." Before these adolescents are faced with a deciding moment, they commit themselves to an identity that does not necessarily fit with their true feelings, but their fears foreclose the opportunity for further exploration.

\section{Identity Moratorium}

Identity moratorium occurs when an individual has faced a crisis but has not committed to an identity. Young women who experience a "deciding moment" or crisis regarding sexual identity may recognize their lesbianism but still feel unable to commit to a lesbian identity. They may take on somewhat of an asexual identity, which allows them to keep from committing themselves to a heterosexual or homosexual identity. Some of the respon- 
dents indicated that their religious beliefs or upbringing kept them from accepting a lesbian identity. To help them cope with the cognitive dissonance, they may suppress parts of themselves, work to pass as heterosexual, or tell themselves that it is only a phase they are experiencing (Taylor, 2000). One of the women interviewed disclosed that she convinced herself that she was not really a lesbian; she had simply fallen in love with a woman. This type of rationalization is not uncommon for adolescent lesbians who have been raised to believe that lesbianism is immoral or unacceptable.

\section{Identity Achievement}

An achieved identity is experienced when an individual has faced a crisis and has committed to an identity. Some women who first experience lesbian feelings may respond very positively to them. Some participants described their response to these early feelings as "excited" and wanting to "meet other lesbians." One woman said that she wanted to "look like a lesbian-clothes, haircut, whatever." However enthusiastic these adolescents may be, there are significant challenges in assuming a lesbian identity. For adolescents who are beginning to feel the need to explore their sexuality coupled with the presence of a divergent sexual interest, it is important that resources be made available to assist them as they move through the identity process.

Studies show that sexual minority individuals are at increased risk of depression, hopelessness, and suicide and that being open about their sexual identity with their family also increases the risk of suicide ( $D^{\prime}$ Augelli et al., 1998; Morrison \& L'Heureux, 2001; Safren \& Heimberg, 1999). Further research shows that same-sex-attracted students may have more negative school attitudes, more trouble in school, and lower grade point averages. Alcohol and drug use frequently increase for sexual minority adolescents (Orenstein, 2001); experiencing, witnessing, and perpetrating violence occur more frequently with sexual minority adolescents (Russell, Franz, \& Driscoll, 2001); and there appear to be greater rates of homelessness and prostitution for sexual minority adolescents (Taylor, 2000).

Adolescents may also feel a sense of being different from others; in the words of one interviewee, she felt "out of place" and "sad in a way." Another talked about the difficulty in trying to find the "right lesbian identity." Another woman claimed that she was "desperate to meet other lesbians." With the risks involved in owning a lesbian identity, it can be vitally important for lesbians to find healthy role models and peers. Research indicates that sexual minority youth who disclosed their identity to their families generally chose to come out to their mothers rather than their fathers (D'Augelli et al., 1998). However, these adolescents run a risk of physical and verbal abuse from family members and a resulting lowered self-esteem because family members are typically less supportive than nonfamily members to whom adolescents disclose. Even as adolescents successfully develop their lesbian identity, they face significant threats to their emotional and physical health. 
Adolescence is a difficult time for any young woman-pressures from families, peers, and oneself make growing up difficult in itself. For young women who experience feelings of same-sex attraction, the identity development process is often much more challenging. The model presented here suggests that the sexual identity formation process may vary among young women and that it may occur in fits and starts. It is imperative that counselors who work with adolescents be aware of the stigmas that may be associated with both seeing a counselor and working through same-sex attraction and lesbian identity development. Counselors need to be sensitive to their clients' feelings and to provide signals of their gay-friendly stance, such as having easily visible decals, bumper stickers visible in prominent places in their office, or gay-affirming books on their bookshelves. Next, the ALIF model is used as a guideline to present suggested counseling interventions appropriate for each phase of sexual identity development.

\section{Diffusion of Lesbian Identity}

If a female adolescent seeks counseling during the diffusion phase, it may be due to her strong feelings of confusion and not fitting in with others. A counselor should feel comfortable helping the client explore her feelings surrounding her sexuality. The counselor may also recognize the need to assist the client in finding ways to develop a more positive self-esteem regarding her difference from others. Most important, a counselor should offer a supportive, nonjudgmental relationship to the client. Studies show that a strong self-esteem and the existence of a nonfamily support system greatly enhance the emotional health of adolescent lesbians (Grossman \& Kerner, 1998; Nesmith, Burton, \& Cosgrove, 1999).

\section{Foreclosure of Lesbian Identity}

The mental health risks of foreclosure are rooted in negative psychological consequences that can arise from repression of same-sex attraction and lesbian identity. This denial and avoidance may lead to suicidal ideations, self-hate, depression, sexual promiscuity, or pregnancy. Counselors may be consulted by parents of these adolescents for reasons such as crisis intervention or suicide assessment. The girls may also seek or be brought to counselors to help them reduce depressive symptoms. An important component of counseling at this time is safe-sex education if the adolescent has chosen to become heterosexually active in order to deny the lesbian feelings. Safe-sex counseling is equally important with lesbian sexual activity.

\section{Moratorium on Lesbian Identity}

Women who are placing a moratorium on sexual identity development may seek counseling early in the stage to help them put to rest their confusing 
feelings. They may need to process the event that led them to recognize their lesbian feelings or to reconcile themselves to being different from other women. Women described this stage as a time when they might withdraw from relationships with friends or boyfriends, thus helping them maintain a distance from committing to a specific identity. Women in this stage may eventually begin to further explore their sexuality, which would require that the counselor offer a supportive, nonjudgmental attitude and provide encouragement to clients for exploration of their identity. Whether a young woman moves from identity diffusion into identity achievement or from identity moratorium into identity achievement, additional changes in her self-perception and others' perception of her will continue.

\section{Achievement of Lesbian Identity}

As young women first self-identify as lesbians and then begin the process of self-disclosure, they may encounter a wide continuum of responses from their families, friends, and communities. These reactions may range from acceptance, to indifference, to rejection. Helping these women cope with any negative reactions from others, which may include verbal, physical, emotional, or sexual abuse, is an important task for counselors, as is providing assistance as these young women navigate their way through the identity process. Depending on current coping strategies, the counselor may need to help the client develop more effective means of dealing with the challenges inherent in lesbian identity in a heterosexually constructed society. Counselors may need to provide information about substance abuse programs and treatment centers for adolescents relying on substance use as their coping method. Counselors should be alert to any suspected familial abuse of their clients and maintain awareness of their responsibilities regarding this issue. Furthermore, treatment for depression and suicide assessment may be called for in some cases. These counseling needs may arise from cases in which the affirmation of lesbian identity leads to isolation and rejection from an adolescent's support system, victimization by others including physical or psychological hate crime tactics, or other forms of discrimination.

At the other end of the spectrum, many adolescent lesbians quickly and successfully move beyond any strong feelings of cognitive dissonance that comes along with lesbian identity development. However, there is often a sense of isolation and loneliness as they seek to connect with other young lesbians. Counselors should be able to provide information on local resources including adolescent support groups and any other organizations that provide safe opportunities for meeting other young lesbians. Self-esteem work may be necessary with the client as she seeks to see herself in a new perspective that may be completely different from her family's and friends' expectations of her. As the adolescent experiments with new behaviors (including dress, courtship, etc.), the counselor can provide positive feedback on her development. Safe-sex information needs to be shared with the adolescent before she becomes sexually active. 
Some young women are aware of the danger in their communities in assuming a lesbian identity. Comments from the women interviewed included fears of "being killed" and thus a tendency to "keep to myself." Another woman felt rejection as an adolescent and knew that she was not accepted by society. At the other end of the continuum, one woman said that she had a great amount of pride and that as an adolescent she would "throw my gayness in their faces." Counselors may need to provide some guidance and support as adolescents develop a minority identity. This can be especially difficult for young women who are members of the racial majority in their community. These young women may also need assistance in handling their feelings of hate and anger. Learning to manage these strong emotions at the same time one is developing one's sexual identity can be very challenging. Adolescence is a time of rebellion, and these young women may need guidance in how to effectively manage their new sexual and adolescent identity. Helping young lesbians get involved in activist organizations in their community can help them channel their energy and enthusiasm for their new community.

\section{CONCLUSION}

Achieving a lesbian identity is a process that occurs over time and typically is not a straightforward, linear process. The ALIF model, based on interviews of adult lesbians regarding their own sexual identity development, provides a structure for understanding levels of development. Because of the nature of qualitative research, the sample size was small, which may limit the generalizability of the findings. However, the recurring patterns and themes apparent in the coming-out narratives of the participants provide solid support for the applicability of this model for this sample. The majority of participants highlighted their teenage years as the time they struggled most with their lesbian identities, although not every participant accepted this identity in adolescence. Some participants entered early adulthood before they were ready to manage their lesbian identity, suggesting that this model may be appropriate for a wider age range of women, from adolescence into adulthood. Further research with women who came out as lesbians in their 30s and onward is needed to better understand similarities between their experiences and those of women who came out in adolescence and early adulthood.

Female adolescents struggling with their sexual identity may benefit from working with an open, well-prepared counselor at many points during the process. School and community counselors should be knowledgeable about local resources, from support groups, to retail outlets, to civil rights organizations. Counselors should help adolescents locate peer groups and role models with whom they can identify as well as help clients find ways in which they can still fit in with existing peer groups. By providing a supportive, nonjudgmental presence, counselors can help clients handle the temptation to use alcohol or other substances that might be used as self-medications in adolescents' efforts to regain self-acceptance. Counselors can play an im- 
portant role in the identity process for young lesbians. Understanding the challenges of sexual identity development and becoming familiar with the local resources will allow school and mental health counselors to become invaluable advocates for their adolescent lesbian clients.

\section{REFERENCES}

Akerlund, M., \& Cheung, M. (2000). Teaching beyond the deficit model: Gay and lesbian issues among African Americans, Latinos, and Asian Americans. Journal of Social Work Education, 36, 279-292.

Cass, V. (1979). Homosexual identity formation: A theoretical model. Journal of Homosexuality, 4, 219-235.

Cass, V. (1984). Homosexual identity formation: Testing a theoretical model. Journal of Sex Research, 20, 143-167.

Cox, S., \& Gallois, C. (1996). Gay and lesbian identity development: A social identity. Journal of Homosexuality, 30(4), 1-30.

D'Augelli, A. R. (1989). Lesbians' and gay men's experiences of discrimination and harassment in a university community. American Journal of Community Psychology, 17, 317-321.

D'Augelli, A. R., Hershberger, S. L., \& Pilkington, N. W. (1998). Lesbian, gay, and bisexual youth and their families' disclosures of sexual orientation and its consequences. American Journal of Orthopsychiatry, 68, 361-371.

Degges-White, S., Rice, B., \& Myers, J. E. (2000). Revisiting Cass's theory of sexual identity formation: Assessing its current applicability to lesbian identity formation. Journal of Mental Health Counseling, 22, 318-333.

Diamond, M. (1999). Homosexuality and bisexuality in different populations. Archives of Sexual Behavior, 22, 291-310.

Erikson, E. (1968). Identity, youth and crisis. New York: Norton.

Fassinger, R. (1991). The hidden minority: Issues and challenges in working with lesbian women and gay men. The Counseling Psychologist, 19, 157-176.

Frable, D. E. S. (1997). Gender, racial, ethnic, sexual, and class identities. Annual Review of Psychology, 48, 139-162.

Gallup, G., Jr., \& Hugick, L. (1990, June). Racial tolerance grows, progress on equality less evident. Gallup Poll Monthly 1990, 297, 22-32.

Grossman, A. H., \& Kerner, M. S. (1998). Self-esteem and supportiveness as predictors of emotional distress in gay male and lesbian youth. Journal of Homosexuality, 35(2), 25-39.

Hequembourg, A. L., \& Farrell, M. P. (1999). Lesbian motherhood: Negotiating marginal mainstream identities. Gender and Society, 13, 540-557.

Marcia, J. E. (1966). Development and validation of ego-identity status. Journal of Personality and Social Psychology, 3, 551-559.

Marcia, J. E. (1987). The identity status approach to the study of ego identity development. In T. Honess \& K. Yardley (Eds.), Self and identity: Perspectives across the lifespan (pp. 161-171). London: Routledge \& Kegan Paul.

McCarn, S. R., \& Fassinger, R. E. (1996). Revisiting sexual minority identity formation: A new model of lesbian identity and its implications for counseling and research. The Counseling Psychologist, 24, 508-534.

McGann, P. J. (1999). Skirting the gender normal divide: A tomboy life story. In M. Romero \& A. Stewarts (Eds.), Women's untold stories: Breaking silence, talking back, voicing complexity (pp. 105-124). New York: Routledge.

Morrison, L. L., \& L'Heureux, J. L. (2001). Suicide and gay, lesbian, bisexual youth: Implications for clinicians. Journal of Adolescence, 24, 39-49.

Nesmith, A. A., Burton, D. L., \& Cosgrove, T. J. (1999). Gay, lesbian, and bisexual youth and young adults' social support in their own words. Journal of Homosexuality, 37(1), 95-108. 
Nichols, S. L. (1999). Gay, lesbian, and bisexual youth: Understanding diversity and promoting tolerance in schools. The Elementary School Journal, 99, 505-519.

Orenstein, A. (2001). Substance use among gay and lesbian adolescents: The CASPAR alcohol and drug education program. Journal of Homosexuality, 41, 1-15.

Russell, S. T., Franz, B. T., \& Driscoll, A. K. (2001). Same-sex romantic attraction and experiences of violence in adolescence. American Journal of Public Health, 91, 903-906.

Safren, S. A., \& Heimberg, R. G. (1999). Depression, hopelessness, suicidality, and related factors in sexual minority and heterosexual adolescents. Journal of Consulting and Clinical Psychology, 67, 859-866.

Savin-Williams, R. C., \& Lenhart, R. E. (1990). AIDS prevention among gay and lesbian youth: Psychological stress and health care intervention guidelines. In D. G. Ostrow (Ed.), Behavioral aspects of AIDS (pp. 75-99). New York: Plenum.

Taylor, H. E. (2000). Meeting the needs of lesbian and gay young adolescents. Clearinghouse, 73, 221-224.

Tomeo, M. E., Templer, D. I., Anderson, S., \& Kotler, D. (2001). Comparative data of childhood and adolescence molestation in heterosexual and homosexual persons. Archives of Sexual Behavior, 30, 535-541.

Whitley, B. E., Jr., \& Egisdóttir, S. (2000). The gender belief system, authoritarianism, social dominance orientation, and heterosexuals' attitudes toward lesbians and gay men. Sex Roles, 42, 947-967.

Whitman, F. L., Daskalos, C., Sobolewski, C. G., \& Padilla, P. (1998). The emergence of lesbian sexuality and identity cross-culturally: Brazil, Peru, the Philippines, and the United States. Archives of Sexual Behavior, 27, 31-56.

Yang, A. S. (1997). Attitudes toward homosexuality. Public Opinion Quarterly, 61, 477-507.

\section{APPENDIX}

\section{Lesbian Identity Level Questionnaire}

Stage 1 Identity Confusion

1. Tell about when you first made a connection between information about homosexuality and yourself. What happened to cause that and how did you feel?

2. How did these feelings influence your self-concept? How did you respond?

3. Describe any activities you engaged in to inhibit or explore these feelings.

Stage 2 Identity Comparison

4. Once you began to believe that you might be lesbian, how did you perceive yourself in relation to peers; family; co-workers; society at large?

5. As you came to accept that you may be homosexual, did you feel a sense of social alienation, perhaps not outright rejection, but a general sense that heterosexual privileges may no longer be assumed? Tell about these feelings.

6. How did these feelings influence your behavior?

7. If you were in a lesbian relationship, did you ever think that your relationship was just a special case, and that you really weren't gay, and that if it wasn't for this relationship you'd be straight? Tell about these feelings.

8. Describe any other ways you internally or externally tried to persuade yourself that even though you were engaging in homosexual behaviors (if you were) that you weren't truly homosexual.

9. At the point that you were struggling with the fact that you might be gay, did you ever try to have all the appearances of a heterosexual? If so, how?

Stage 3 Identity Tolerance

10. Tell about when you first thought, "I probably am gay."

11. Describe your first attempts to meet/interact with other homosexuals and the feelings that accompanied these experiences.

12. If you never pursued the homosexual subculture, what kept you from doing so?

(Continued on next page) 


\section{APPENDIX (Continued) \\ Lesbian Identity Level Questionnaire}

Stage 4 Identity Acceptance

13. What feelings did your first experiences with other homosexuals create for you? How did they affect your view of yourself; your identity; your self-concept; your behavior?

14. Have you ever felt like you fit into the homosexual community? If you have, tell about when you first felt like you fit there and how this made you feel.

15. Tell about when you first accepted the self-label of lesbian and the feelings that accompanied this.

Stage 5 Identity Pride

16. Have you ever had an "us vs. them" attitude regarding the gay and lesbian population and the straight world? If so, describe these feelings.

17. Tell about any activities in which you've participated that you view as homosexual activism.

18. If you've ever seen your homosexuality as your main identity, what circumstances led to this view?

19. Tell about any times you have consciously chosen to make an issue of your homosexuality to straight people.

Stage 6 Identity Synthesis

20. If you have ever viewed homosexuality as your main identity, do you continue to hold this view? If no, relate any changes in how you've defined your identity.

21. Describe how you currently view yourself as a gay person in the predominantly straight world.

22. What are your feelings regarding your interest and ability in maintaining significant relationships with both heterosexuals and homosexuals?

23. Describe how well you feel your life is integrated-your homosexual self, your professional self, your social self, etc.?

24. Describe the most important obstacles you had to face in order to accept your homosexuality?

25. How do you sum up your coming out experience?

See Cass (1979) and Degges-White, Rice, and Myers, 2000. 
Copyright of Journal of Humanistic Counseling, Education \& Development is the property of American Counseling Association. The copyright in an individual article may be maintained by the author in certain cases. Content may not be copied or emailed to multiple sites or posted to a listserv without the copyright holder's express written permission. However, users may print, download, or email articles for individual use. 